\title{
BMJ Open Serum 25-hydroxyvitamin D level in relation to weight change and the risk of weight gain in adults of normal weight at baseline: the Norwegian HUNT cohort study
}

\author{
Adaline Heitz, ${ }^{1}$ Xiao-Mei Mai (D) , ${ }^{1}$ Yue Chen, ${ }^{2}$ Yi-Qian Sun (D) ${ }^{3,4,5}$
}

To cite: Heitz A, Mai X$M$, Chen Y, et al. Serum 25-hydroxyvitamin D level in relation to weight change and the risk of weight gain in adults of normal weight at baseline: the Norwegian HUNT cohort study. BMJ Open 2020;10:e039192. doi:10.1136/ bmjopen-2020-039192

- Prepublication history and supplemental materials for this paper are available online. To view these files, please visit the journal online (http://dx.doi. org/10.1136/bmjopen-2020039192).

Received 07 April 2020 Revised 28 July 2020 Accepted 18 August 2020

Check for updates

(C) Author(s) (or their employer(s)) 2020. Re-use permitted under CC BY-NC. No commercial re-use. See rights and permissions. Published by BMJ.

For numbered affiliations see end of article.

Correspondence to

Dr Yi-Qian Sun;

yi-qian.sun@ntnu.no

\section{ABSTRACT}

Objective We sought to investigate the relationship of serum 25-hydroxyvitamin D (25(OH)D) level with weight change and the risk of weight gain in an adult population who had normal weight at baseline and were followed up for 11 years.

Design A population-based prospective cohort study.

Setting Nord-Trøndelag, Norway.

Participants The study included 1501 adults who participated in the second and third surveys of the NordTrøndelag Health Study (HUNT2 (1995-1997) and HUNT3 (2006-2008)) and had a normal body mass index $\geq 18.5$ and $<25.0 \mathrm{~kg} / \mathrm{m}^{2}$ at baseline.

Primary and secondary outcome measures Relative weight change (\%) was calculated as ((HUNT3 weightHUNT2 weight)/HUNT2 weight×100). Relative annual weight change (\%) was calculated as (relative weight change/follow-up years $\times 100$ ). Clinical weight gain was defined as relative weight change $\geq 5 \%$ over the 11 years, while annual weight gain was defined as relative annual weight change $>1.25 \%$.

Methods Multiple regression models were used to estimate adjusted coefficients for the relative annual weight change and risk ratios (RRs) for the risk of clinical weight gain and of annual weight gain.

Results Each $25 \mathrm{nmol} / \mathrm{L}$ increase in season-standardised serum 25(OH)D level at baseline was associated with a reduction of $0.05 \%(95 \% \mathrm{Cl}-0.11$ to 0.01$)$ for relative annual weight change, a $10 \%$ (RR $0.90,95 \% \mathrm{Cl} 0.82$ to 0.97 ) reduced risk of clinical weight gain, and a $19 \%$ (RR $0.81,95 \% \mathrm{Cl} 0.65$ to 1.00 ) reduced risk of annual weight gain. A statistically significant trend was evident for the risk of clinical weight gain when $25(\mathrm{OH}) \mathrm{D}$ levels were treated as a categorical variable $(p=0.006)$.

Conclusions The findings suggested an inverse association of serum $25(\mathrm{OH}) \mathrm{D}$ level with the risk of clinical weight gain in adults who had normal weight at baseline over 11 years' follow-up.

\section{INTRODUCTION}

The prevalence of overweight and obesity has increased rapidly in the past several decades, accounting for four million deaths worldwide in 2015 alone. ${ }^{12}$ Meanwhile, vitamin
Strengths and limitations of this study

- This study was one of the few cohort studies that only followed up adults of normal weight at baseline.

- The 11-year follow-up period allowed us to evaluate the influence of vitamin $D$ on the long-term weight change in the study population.

- We defined the risk of clinical weight gain and the risk of annual weight gain based on cut-off values established in previous research instead of using arbitrary cut-off values.

- The sample size was sufficient to perform stratified analyses by age, sex and leisure time physical activity.

- Residual confounding due to unknown or unmeasured factors cannot be excluded, for instance, information on dietary factors was not collected in the Nord-Trøndelag Health Study 2 Questionnaire.

D deficiency is also a global health issue. ${ }^{3}$ There may exist a bidirectional relationship between vitamin D deficiency and obesity. Obese individuals tend to have a lower level of vitamin D compared with normal weight individuals. ${ }^{4}$ Possible explanations for this association include volumetric dilution of serum vitamin D levels in obese individuals ${ }^{5}$ and sequestration of vitamin $\mathrm{D}$ in adipose tissue. ${ }^{6}$ It has also been hypothesised that low vitamin D status may contribute to the development of obesity. ${ }^{7}$

Prospective studies on the vitamin D and adiposity association in adults have yielded inconsistent results. ${ }^{8-12}$ A 4-year follow-up study of Spanish adults found a significant association between low 25-hydroxyvitamin D $[25(\mathrm{OH}) \mathrm{D}]$ and an increased risk of obesity. ${ }^{9}$ An 11-year follow-up study of youngto-middle-aged Norwegian adults showed a similar association between $25(\mathrm{OH}) \mathrm{D}$ and the risk of obesity. ${ }^{10}$ However, other studies 
found no association of serum $25(\mathrm{OH}) \mathrm{D}$ level with body mass index (BMI) change in adult Hispanic and African Americans ${ }^{8}$ or with weight change in elderly women. ${ }^{11}$ In the latter study, however, women with higher serum $25(\mathrm{OH}) \mathrm{D}$ concentrations tended to gain less weight in a subgroup of normal weight at baseline. ${ }^{11}$

There is evidence that adults with normal body weight at baseline tend to experience a greater weight gain than those being overweight or obese. ${ }^{13}$ Vitamin D may have a preventive effect on adiposity for individuals of normal weight but no treatment effect for the already overweight or obese individuals. ${ }^{14-18}$ Thus, the objective of this study was to investigate the relationship of serum $25(\mathrm{OH})$ $\mathrm{D}$ level with weight change and the risk of weight gain among adults with normal weight at baseline who participated in the Nord-Trøndelag Health Study (HUNT) and were followed up for over 11 years.

\section{METHODS}

\section{Study population}

HUNT is a large and comprehensive health study in Norway; it has previously been described in detail. ${ }^{19}$ Data from the second and third surveys of HUNT, HUNT2 (1995-1997) and HUNT3 (2006-2008) were used for this study. All residents aged $\geq 20$ years in the Nord-Trøndelag region of Norway were invited to participate in each of the surveys. Of the approximately 93000 individuals $(>97 \%$ were ethnic Norwegians) invited to participate in HUNT2, 65229 took part in the study (response rate $70 \%)$ and a $10 \%$ random sample $(\mathrm{n}=6613)$ was selected for measurement of serum $25(\mathrm{OH}) \mathrm{D}$ levels. Baseline $25(\mathrm{OH}) \mathrm{D}$ levels were available for 6377 participants with sufficient blood sample volume, of which 3671 (57.6\%) participated in HUNT3 for an average 11-year follow-up and had complete data on the exposure and outcome variables. The general response rate for the HUNT3 survey was $54 \%$. Among the 3671 participants, those of normal weight at baseline were included in the final analytical sample $(\mathrm{n}=1501)$ (figure 1). Normal weight at baseline was defined as having a BMI of $\geq 18.5$ and $<25 \mathrm{~kg} / \mathrm{m}^{2}$ in HUNT2 using the standard WHO cut-off points. ${ }^{20}$

\section{Serum 25(OH)D level in HUNT2 as exposure variable}

Blood samples were collected from the HUNT2 participants and stored in $-70^{\circ} \mathrm{C}$ freezers. LIAISON $25-\mathrm{OH}$ Vitamin D TOTAL assay (DiaSorin, Saluggia, Italy) was used to determine baseline serum $25(\mathrm{OH}) \mathrm{D}$ levels. This fully automated chemiluminescent immunoassay has a detection range of 10-375 nmol/L and intraassay and interassay coefficients of variation of $4 \%$ and $8 \%$, respectively. Because seasonal fluctuations in $25(\mathrm{OH}) \mathrm{D}$ levels were expected due to the high-latitude geographical position of Norway (online supplemental figure 1A), a cosinor model based on month of blood draw was used to calculate season-standardised $25(\mathrm{OH}) \mathrm{D}$ level $(\mathrm{nmol} / \mathrm{L})$ that represents the annual average value of $25(\mathrm{OH}) \mathrm{D}$ for each participant. The standardised $25(\mathrm{OH}) \mathrm{D}$ levels were highly

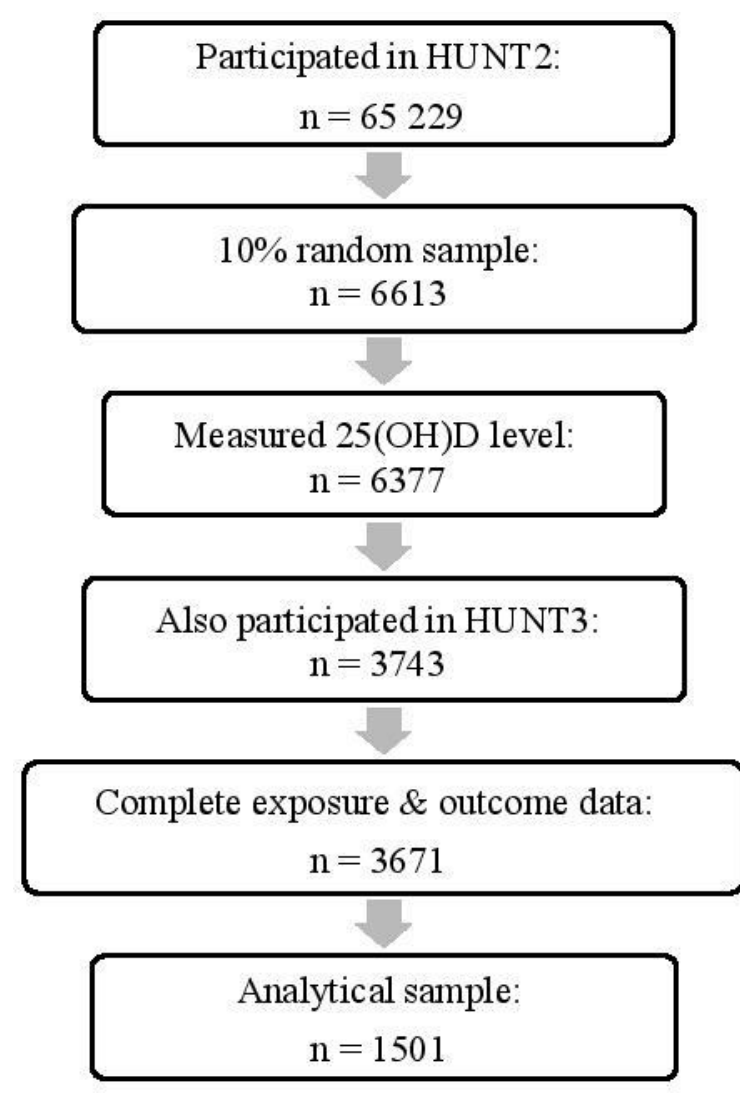

Figure 1 Selection of the study population and analytical sample, Nord-Trøndelag Health Study (HUNT). Analytical sample comprised of participants with normal weight (body mass index $\geq 18.5$ and $<25 \mathrm{~kg} / \mathrm{m}^{2}$ ) at baseline and complete data on serum 25-hydroxyvitamin D level (25(OH)D), height and body weight.

correlated with the measured $25(\mathrm{OH})$ D levels (correlation coefficient $=0.96$, online supplemental figure $1 \mathrm{~B}$ ). This model was based on the $10 \%$ random sample of the HUNT2 participants who had available serum 25(OH)D levels $(n=6377)$. It has been suggested that use of annual average $25(\mathrm{OH}) \mathrm{D}$ levels is a more effective method of controlling for season of blood draw than inclusion of season in adjusted models because it appears to minimise mean squared error. ${ }^{21}$ The season-standardised $25(\mathrm{OH})$ D levels were used as a continuous variable and were also treated as a categorical variable classified by the following cut-off values $(\mathrm{nmol} / \mathrm{L}):<30.0,30.0-49.9,50.0-74.9$ and $\geq 75.0$. These categories were established based on the Institute of Medicine of the National Academies. ${ }^{22}$

\section{Covariates}

Information on covariates at baseline was collected via questionnaires. Smoking status was categorised as never, former and current smokers. Education was categorised as $<10,10-12$ and $\geq 13$ years. The presence of economic difficulties (yes/no) was defined using the following question: 'During the last year, has it at any time been difficult to meet the costs of food, transportation, housing and such?' Alcohol consumption was categorised as 0 (abstainer), $1-4$ and $\geq 5$ times/month. Leisure time 
physical activity level was classified into four categories based on reported average hours of light (no sweating or not being out of breath) and hard (sweating or out of breath) physical activity: inactive, low, moderate or high. Categorisation of physical activity in the HUNT study has been described in detail previously. ${ }^{23}$ Total sitting time was used as a marker for sedentary lifestyle and was categorised as $<4,5-7$ and $\geq 8$ hours/day. Chronic illness was a variable generated from responses to several questions on major somatic diseases (Have you had or do you have any of the following diseases: myocardial infarction (heart attack)/angina pectoris (chest pain)/stroke (brain haemorrhage)/diabetes/cancer? yes/no). Separate 'unknown' categories were generated and included in primary analyses for participants with missing information for smoking status, education, economic difficulties, alcohol consumption, leisure time physical activity, sedentary lifestyle and chronic illness. These categorisations have been used in previous HUNT publications. ${ }^{23-25}$

\section{Outcome variables}

Measurement of body height and weight were performed at clinical examinations in both HUNT2 and HUNT3 by trained health professionals. Participants wore light clothing and no shoes during the measurements. Height was measured to the nearest $1.0 \mathrm{~cm}$ and weight to the nearest $0.5 \mathrm{~kg}$. Quality assurance was performed to check for outliers for the measurements of weight and height. The height variable was checked between the HUNT surveys and there were no obvious errors. We calculated relative weight change instead of absolute weight change to take the baseline body weight into account. Relative weight change $(\%)$ was calculated as [(HUNT3 weight-HUNT2 weight)/HUNT2 weight $\times 100$ ] (online supplemental table 1). Relative annual weight change (\%) was calculated as (relative weight change/follow-up years $\times 100)$. Clinical weight gain was defined as a relative weight change $\geq 5 \%$ over the 11-year follow-up period. Annual weight gain was defined as a relative annual weight change $>1.25 \%$. These cut-off values were established in previous publications. ${ }^{26}{ }^{27}$ Annual weight gain redefined as a relative annual weight change $>1.5 \%$ and absolute weight change were also used as outcomes for sensitivity analyses.

\section{Statistical analysis}

Descriptive statistics were calculated for the analytical sample of the normal weight adults $(\mathrm{n}=1501)$ and stratified by the categories of serum $25(\mathrm{OH}) \mathrm{D}$ level for the following covariates at baseline: age, sex, smoking status, education, economic difficulties, alcohol consumption, leisure time physical activity, total sitting time and chronic illness. All covariates were retained in adjusted models due to plausible confounding relationships with the exposure and outcome variables. Differences in distribution of baseline covariates between the $25(\mathrm{OH}) \mathrm{D}$ level categories were assessed using analysis of variance for continuous variables and the Pearson $\chi^{2}$ test for categorical variables.
Multivariable linear regression was used to evaluate the association between baseline $25(\mathrm{OH}) \mathrm{D}$ levels and the relative annual weight change between HUNT2 and HUNT3; crude and adjusted coefficients and 95\% CI were estimated. Poisson regression with robust error variance was used to investigate the relationship between baseline serum $25(\mathrm{OH}) \mathrm{D}$ levels and risk of clinical weight gain as well as risk of annual weight gain as they were common outcomes $^{28}$; crude and adjusted risk ratios (RRs) and 95\% CIs were estimated. The linear association was tested by treating serum $25(\mathrm{OH}) \mathrm{D}$ categories as an ordinal variable versus as a categorical variable using the likelihood ratio test (LRT). As the LRT did not show deviation from a linear association with the relative annual weight change $(\mathrm{p}=0.90)$, the lowest serum $25(\mathrm{OH}) \mathrm{D}$ category $(<30.0 \mathrm{nmol} / \mathrm{L})$ was used as the referent group and the $25(\mathrm{OH}) \mathrm{D}$ level was also used as a continuous variable in the analyses.

Effect modification by age, sex and leisure time physical activity for the risk of clinical weight gain was evaluated using the Wald test. Age and physical activity were categorised as dichotomous variables with similar numbers of participants in each stratum to maintain statistical power. Age was categorised as $<45$ and $\geq 45$ years, and the four physical activity categories were collapsed into less active (physical activity level being inactive or low) and more active (physical activity level being moderate or high) groups. All statistical analyses were conducted using Stata/MP V.15.1 (StataCorp LP, College Station, Texas).

\section{Patient and public involvement}

There was no patient or public involvement in the design or data analysis of this study.

\section{RESULTS}

Study participants were on average 43.4 years of age at baseline (table 1). There were more women $(61.4 \%)$ than men $(38.7 \%)$. The distribution of participants in the four baseline serum $25(\mathrm{OH}) \mathrm{D}$ categories was $8.1 \%$ in $<30.0 \mathrm{nmol} / \mathrm{L}, 41.5 \%$ in $30.0-49.9 \mathrm{nmol} / \mathrm{L}, 41.8 \%$ in $50.0-74.9 \mathrm{nmol} / \mathrm{L}$ and $8.6 \%$ in $\geq 75.0 \mathrm{nmol} / \mathrm{L}$. Higher serum 25(OH)D levels were associated with older age, higher education and higher physical activity as well as being male and never smokers compared with $25(\mathrm{OH})$ $\mathrm{D}<30.0 \mathrm{nmol} / \mathrm{L}$.

In general, a lower mean of relative annual weight change was present in all categories with higher $25(\mathrm{OH})$ D levels compared with the $<30.0 \mathrm{nmol} / \mathrm{L}$ category (table 2). Every 25-unit increase in serum $25(\mathrm{OH}) \mathrm{D}$ was associated with a reduction of relative annual weight change by $0.05 \%$ (95\% CI -0.11 to 0.01 ), which corresponds to a reduction of $369 \mathrm{~g}$ in absolute weight change during the 11 years' follow-up for a person with the average weight of $67 \mathrm{~kg}$ in HUNT2. Similar but weaker associations were observed for absolute weight change compared with the relative annual weight change (online supplemental table 2). 
Table 1 Baseline characteristics of subjects overall and by baseline serum 25(OH)D levels in the HUNT2 study, 1995-1997

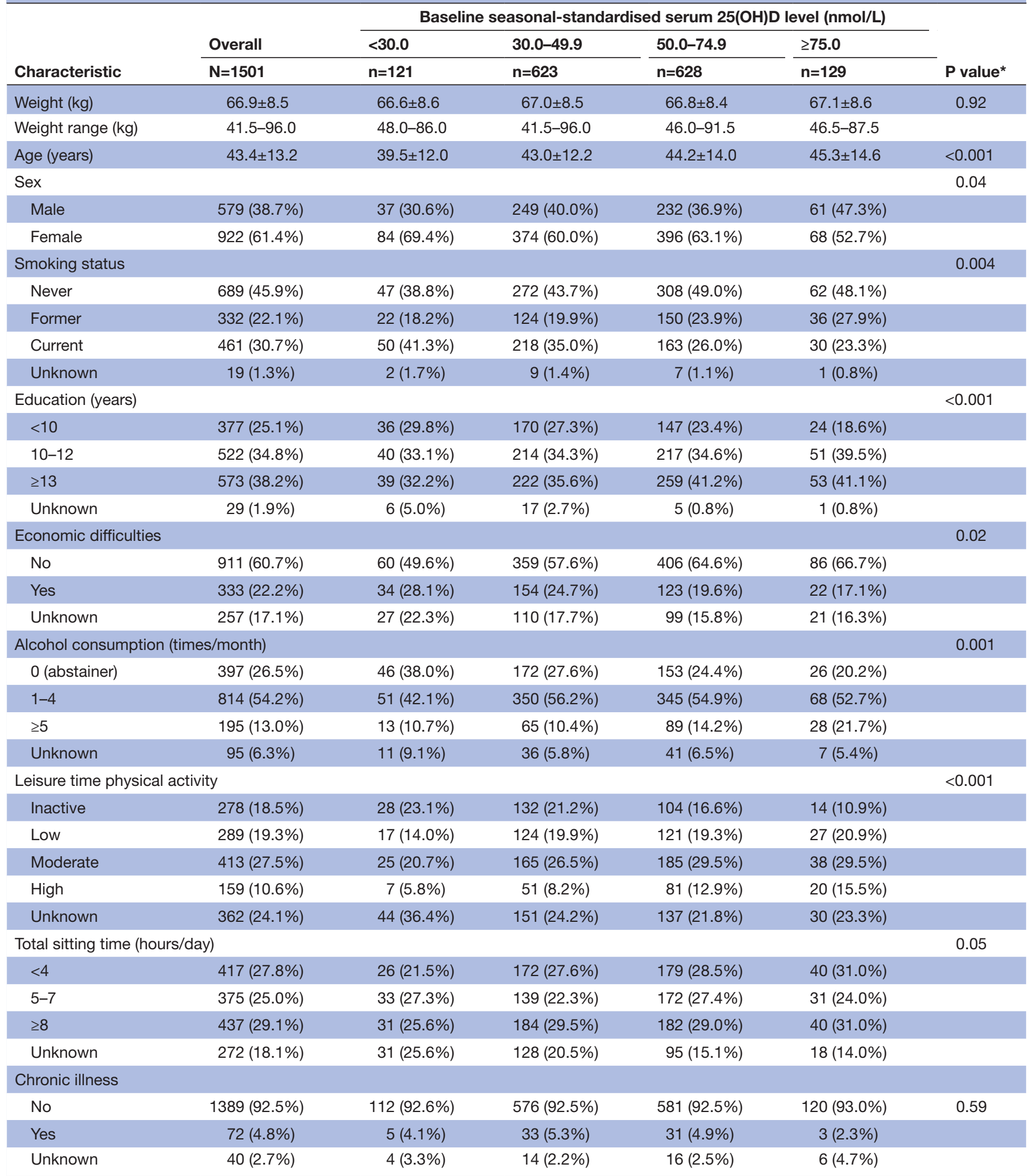

Data are given as number of subjects (column percentage) or mean \pm SD; percentages (\%) may not add up to $100 \%$ due to rounding.

${ }^{*}$ Comparisons between baseline serum $25(\mathrm{OH}) \mathrm{D}$ level categories; $p$ values reported using Pearson $\chi^{2}$ tests for categorical covariates or analysis of variance tests for continuous covariates.

HUNT2, Nord-Trøndelag Health Study 2; 25(OH)D, 25-hydroxyvitamin D.

Overall, the risk of clinical weight gain was $47.2 \%$ and the risk of annual weight gain was $13.4 \%$ for the 11 -year study period (table 3). There was an inverse association of the other $25(\mathrm{OH}) \mathrm{D}$ categories with the risk of clinical weight gain and the risk of annual weight gain compared with the $25(\mathrm{OH}) \mathrm{D}<30.0 \mathrm{nmol} / \mathrm{L}$ category, and a statistically 
Table 2 Association between baseline seasonal-standardised serum 25(OH)D level and relative annual weight change from 1995-1997 to 2006-2008

\begin{tabular}{|c|c|c|c|c|c|}
\hline \multirow[b]{2}{*}{$\begin{array}{l}\text { Seasonal-standardised } \\
\text { serum } 25(\mathrm{OH}) \mathrm{D}(\mathrm{nmol} / \mathrm{L})\end{array}$} & \multirow[b]{2}{*}{$\begin{array}{l}\text { Participants } \\
\text { (n) }\end{array}$} & \multicolumn{2}{|c|}{ Crude model } & \multicolumn{2}{|c|}{ Adjusted model* } \\
\hline & & $\begin{array}{l}\text { Mean } \\
(\%)\end{array}$ & $\begin{array}{l}\text { Coefficient }(95 \% \mathrm{Cl}) \\
(\%)\end{array}$ & $\begin{array}{l}\text { Mean } \\
(\%)\end{array}$ & $\begin{array}{l}\text { Coefficient }(95 \% \mathrm{Cl}) \\
(\%)\end{array}$ \\
\hline$<30.0$ & 121 & 0.60 & 0 (reference) & 0.50 & 0 (reference) \\
\hline $30.0-49.9$ & 623 & 0.51 & $-0.09(-0.25$ to 0.07$)$ & 0.49 & $-0.01(-0.16$ to 0.14$)$ \\
\hline$P$ for trend & & & 0.001 & & 0.12 \\
\hline Continuous & 1501 & & $-0.11(-0.17$ to -0.05$)$ & & $-0.05(-0.11$ to 0.01$)$ \\
\hline
\end{tabular}

For categorical $25(\mathrm{OH}) \mathrm{D}$, 'mean' is the mean value of relative annual weight change in percentage in the $25(\mathrm{OH}) \mathrm{D}$ categories; 'coefficient' is the mean difference in the relative annual weight change in percentage among the other $25(\mathrm{OH}) \mathrm{D}$ categories compared with the reference category $(<30.0)$.

For continuous $25(\mathrm{OH}) \mathrm{D}$, 'coefficient' is the difference in the relative annual weight change in percentage per $25 \mathrm{nmol} / \mathrm{L}$ increase in $25(\mathrm{OH}) \mathrm{D}$. ${ }^{*}$ Adjusted for age, sex, smoking status, education, economic difficulties, alcohol consumption, leisure time physical activity, total sitting time and chronic illness.

25(OH)D, 25-hydroxyvitamin D.

significant trend was evident for the risk of clinical weight gain $(p=0.006)$. The adjusted $R R$ for $25(\mathrm{OH}) \mathrm{D} \geq 75.0$ $\mathrm{nmol} / \mathrm{L}$ versus $<30.0 \mathrm{nmol} / \mathrm{L}$ was 0.77 (95\% CI 0.59 to 1.01) for the risk of clinical weight gain and was 0.52 (95\% CI 0.26 to 1.07) for the risk of annual weight gain. Per $25 \mathrm{nmol} / \mathrm{L}$ increase in the $25(\mathrm{OH}) \mathrm{D}$ level was associated with a $10 \%$ (RR $0.90,95 \%$ CI 0.82 to 0.97 ) reduced risk of clinical weight gain and a $19 \%$ (RR $0.81,95 \%$ CI 0.65 to 1.00 ) reduced risk of annual weight gain. In one of the sensitivity analyses, $132(8.8 \%)$ individuals were defined as a relative annual weight change $>1.5 \%$. Similar results were demonstrated for serum $25(\mathrm{OH}) \mathrm{D}$ level as a categorical or continuous variable associated with the risk of relative annual weight change $>1.5 \%$ (online supplemental table 3).

We also evaluated the association between serum $25(\mathrm{OH}) \mathrm{D}$ as a continuous variable and the risk of clinical weight gain stratified by age, sex and leisure time physical activity (table 4). The risk of clinical weight gain over the 11-year follow-up period was higher among participants $<45$ years of age $(58.2 \%)$ than older counterparts $(32.8 \%)$, and in males $(49.9 \%)$ than females $(45.4 \%)$. However, the risk was not different between those who were less active and those who were more active. As shown in table 4, a significant reduction in the risk of clinical weight gain per $25 \mathrm{nmol} / \mathrm{L}$ increase in serum $25(\mathrm{OH})$ D was observed among female participants (RR 0.84, $95 \%$ CI 0.75 to 0.94 ) but not in males ( $p$ for interaction=0.04). Each $25 \mathrm{nmol} / \mathrm{L}$ increase in serum $25(\mathrm{OH}) \mathrm{D}$ was associated with a $18 \%$ reduced risk of clinical weight gain among participants who were less active, but there appeared no association for those who were more active ( $p$ for interaction=0.07). Age did not modify the association between $25(\mathrm{OH}) \mathrm{D}$ and the risk of clinical weight gain ( $\mathrm{p}$ for interaction $=0.67$ ).

\section{DISCUSSION}

Based on data from 1501 adults who had normal weight at baseline and were followed up for 11 years, we found that each 25-unit increase in serum $25(\mathrm{OH}) \mathrm{D}$ level was associated with a small reduction of $0.05 \%$ in relative annual weight change, a $10 \%$ reduced risk of clinical weight gain, and a $19 \%$ reduced risk of annual weight gain. The associations showed a statistically significant trend for the risk of clinical weight gain when serum $25(\mathrm{OH}) \mathrm{D}$ levels were used as a categorical variable. The association between $25(\mathrm{OH}) \mathrm{D}$ and risk of clinical weight gain seemed to be modified by sex and leisure time physical activity but not by age.

Several prospective studies have investigated the association of serum vitamin $\mathrm{D}$ level with adiposity in adults and shown inconsistent results. ${ }^{8-12}$ The inconsistencies among studies could be partly explained by differences in choice and categorisation of exposure and outcome variables. Different cut-off values were used to categorise the vitamin D groups ${ }^{9-11}$ or vitamin D level was treated solely as a continuous variable. ${ }^{812}$ The outcome variables varied including the risk of obesity, ${ }^{9}{ }^{10}$ change in BMI, body weight and waist circumference, ${ }^{89} 12$ or alternative adiposity measures. ${ }^{8}$ Additionally, difference in follow-up duration may contribute to the discrepancy among studies. Vitamin D might have a preventive effect on adiposity but no treatment effect on overweight and obesity. ${ }^{14-18}$ Therefore, our study only selected adults who had a normal weight at baseline. Our findings of the inverse associations in adults of normal weight were consistent with those of a previous study of 4659 elderly women; in that study, women with higher baseline $25(\mathrm{OH}) \mathrm{D}$ level gained less weight over 4.5 years of follow-up in a subgroup of predominately normal weight at baseline. ${ }^{11}$ 


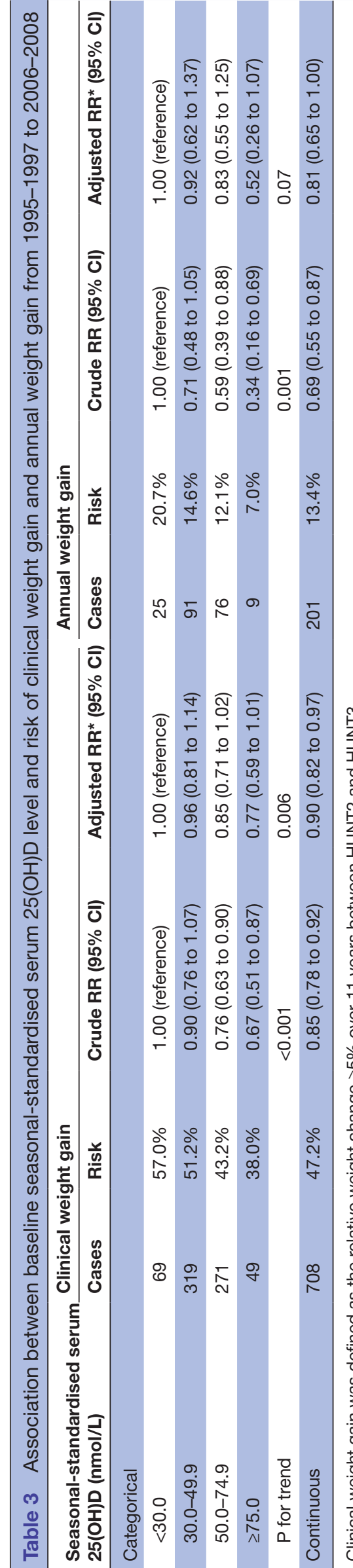

Randomised controlled trials (RCT) have in general shown no effect of vitamin D supplementation on weight change over time. ${ }^{14-18}$ These trials have mostly been conducted in overweight or obese individuals. Only one large RCT showed that participants of normal weight who received a daily supplement of calcium and vitamin D experienced significantly lower average annual weight gain and a lower risk of weight gain over 7 years of follow-up. ${ }^{29}$ However, it is impossible to isolate the effects of calcium and vitamin $\mathrm{D}$ on weight change in this study.

The exact mechanisms by which serum $25(\mathrm{OH}) \mathrm{D}$ might affect change in body weight have not been well established. Several plausible pathways have been proposed. High vitamin $\mathrm{D}$ and calcium, and the consequent low level of parathyroid hormone, may play a regulatory role in adipocytes by promoting lipolysis and inhibiting lipogenesis. ${ }^{30} 31$ High level of vitamin $\mathrm{D}$ and calcium may increase whole body fat oxidation and faecal fat excretion. Emerging evidence suggests that vitamin $\mathrm{D}$ has a potential to improve insulin sensitivity that would reduce food intake..$^{30}$ In addition, in vitro and animal studies have shown that the bioactive form of vitamin $\mathrm{D}, 1,25$-dihydroxyvitamin $\mathrm{D}$ can induce mature adipocytes death by apoptosis ${ }^{32}$; in a high-fat diet-induced obesity mouse model, an increased intake of vitamin $\mathrm{D}$ is associated with a decreased weight of white adipose tissue due to induction of apoptosis.

Our study demonstrated possible effect modification by sex. Female participants had a $16 \%$ reduction in risk of clinical weight gain per $25 \mathrm{nmol} / \mathrm{L}$ increase in serum $25(\mathrm{OH})$ $\mathrm{D}$, whereas there was no association in males. These findings indicated that low vitamin $\mathrm{D}$ could be a more important risk factor for long-term clinical weight gain for women than men. Women have been reported to be at increased risk for both vitamin D deficiency and obesity. ${ }^{333}$ In the current study, $9.1 \%$ of women had serum $25(\mathrm{OH}) \mathrm{D}$ level $<30.0 \mathrm{nmol} / \mathrm{L}$ compared with $6.4 \%$ in men. A recent Finnish study reported that sufficient vitamin D level ( $\geq 50 \mathrm{nmol} / \mathrm{L})$ may be a protective factor for weight gain in men but not in women. ${ }^{34}$ This Finnish study, however, included a general population rather than adults of normal weight at baseline. Our finding was consistent with results from a German cohort of older adults in which higher vitamin $\mathrm{D}$ status was associated with a lower odds ratio for body fat gain in women but not in men in a 3-year follow-up study. ${ }^{35}$

Our results were also indicative of potential effect modification by leisure time physical activity. Participants who were less active had a $18 \%$ reduced risk of clinical weight gain per $25 \mathrm{nmol} / \mathrm{L}$ increase in serum $25(\mathrm{OH}) \mathrm{D}$, while the association was much weaker for participants who were more active. These results are consistent with the findings from a previous RCT on vitamin D supplementation. ${ }^{29}$ Women taking the vitamin D supplement experienced smaller average annual weight gain in the lowest physical activity group, whereas annual weight gain did not differ between women taking the supplement and placebo who had higher physical activity. Since high level of physical activity is an important preventive factor for weight gain and is associated with elevated serum $25(\mathrm{OH}) \mathrm{D},{ }^{36}{ }^{37}$ it might cancel out the harmful effect of low vitamin $\mathrm{D}$ on the risk of weight gain. 
Table 4 Association between baseline seasonal-standardised serum 25(OH)D level and risk of clinical weight gain over 11year follow-up, stratified by age, sex and leisure time physical activity level

\begin{tabular}{|c|c|c|c|c|c|}
\hline & Participants (n) & Cases & Risk & Adjusted RR* (95\% Cl) & P for interaction \\
\hline$<45$ & 851 & 495 & $58.2 \%$ & 0.90 (0.82 to 0.99$)$ & 0.67 \\
\hline \multicolumn{6}{|l|}{ Sex } \\
\hline Male & 579 & 289 & $49.9 \%$ & 0.99 (0.88 to 1.13$)$ & 0.04 \\
\hline \multicolumn{6}{|c|}{ Leisure time physical activity } \\
\hline Less active & 567 & 280 & $49.4 \%$ & $0.82(0.71$ to 0.94$)$ & 0.07 \\
\hline More active & 572 & 286 & $50.0 \%$ & 0.96 (0.85 to 1.09$)$ & \\
\hline
\end{tabular}

Clinical weight gain was defined as relative weight change $\geq 5 \%$ over 11 years between HUNT2 and HUNT3.

Less active referred to physical activity level being inactive or low; more active referred to physical activity level being moderate or high.

${ }^{*}$ Risk ratio per $25 \mathrm{nmol} / \mathrm{L}$ increase in $25(\mathrm{OH}) \mathrm{D}$; poisson regression adjusted for age, sex, smoking status, education, economic difficulties, alcohol consumption, leisure time physical activity, total sitting time and chronic illness.

HUNT, Nord-Trøndelag Health Study; 25(OH)D, 25-hydroxyvitamin D; RR, risk ratio.

To our knowledge, this prospective cohort study is one of the few to investigate the relationship of serum $25(\mathrm{OH})$ $\mathrm{D}$ with weight change and risk of weight gain in adults of normal weight. We mainly assessed the relative instead of absolute weight change to take the baseline body weight into account. We also defined the risk of clinical weight gain and the risk of annual weight gain based on cut-off values established in previous research instead of using arbitrary cut-off values. ${ }^{26}{ }^{27}$ The sample size was sufficient to perform stratified analyses by age, sex and leisure time physical activity. Inclusion of comprehensive information on relevant covariates minimised confounding in adjusted models. Use of seasonal-standardised serum $25(\mathrm{OH}) \mathrm{D}$ as opposed to adjustment for season of blood draw allowed for minimisation of mean squared error, as mentioned previously. ${ }^{21}$ This helped provide more accurate estimates of association measures. Furthermore, the 11-year follow-up period allowed us to evaluate the influence of vitamin $\mathrm{D}$ on the long-term weight change in the study population.

There were several limitations related to our study. Data on lifestyle factors were self-reported, which were subject to misclassification. Our analysis did not account for changes in the serum 25(OH)D level or lifestyle factors that might have taken place over the course of follow-up. Although an inverse association of serum $25(\mathrm{OH}) \mathrm{D}$ with the risk of weight gain was observed, residual confounding due to missing data of the covariates or unknown or unmeasured factors cannot be excluded. For instance, information on dietary factors was not collected in the HUNT2 Questionnaire. Socioeconomic status can reasonably be used as a proxy for dietary factors due to the observation that diet quality tends to vary by socioeconomic status. ${ }^{38}$ Our results would have been confounded if the dietary factors were not associated with any of the covariates adjusted in the models. Thus, caution should be taken when we draw conclusions owing to the possibilities of residual confounding and some of the results at borderline statistical significance. Moreover, based on the estimate size for relative annual weight change or absolute weight change per 25 units increase in $25(\mathrm{OH}) \mathrm{D}$, the role of vitamin $\mathrm{D}$ in weight change is likely far less important than dietary factors and physical activity. Additionally, in the stratified analysis, serum $25(\mathrm{OH}) \mathrm{D}$ could only be evaluated as a continuous variable due to concerns about statistical power. Evaluation of leisure time physical activity as an effect modifier could only be performed in 1139 of the 1501 participants due to missing data on baseline physical activity. Thus, possible effect modification by age, sex and physical activity should be confirmed in different populations with a larger sample size.

In summary, our 11-year follow-up study suggested that higher serum 25(OH)D level was associated with a reduced risk of weight gain in adults who had normal weight at baseline, more evidently with the risk of clinical weight gain. The potential causal role of vitamin $\mathrm{D}$ in weight gain warrants further investigation in Norwegian and other ethnic populations.

\section{Author affiliations}

${ }^{1}$ Department of Public Health and Nursing, Norwegian University of Science and Technology, Trondheim, Norway

${ }^{2}$ School of Epidemiology and Public Health, Faculty of Medicine, University of Ottawa, Ottawa, Ontario, Canada

${ }^{3}$ Department of Clinical and Molecular Medicine, Norwegian University of Science and Technology, Trondheim, Norway

${ }^{4}$ Department of Pathology, Clinic of Laboratory Medicine, St. Olavs Hospital, Trondheim, Norway

${ }^{5}$ Center for Oral Health Services and Research, Mid-Norway (TkMidt), Trondheim, Norway

Acknowledgements The Nord-Trøndelag Health Study (HUNT) Study is a collaboration between HUNT Research Centre (Faculty of Medicine and Health Sciences, Norwegian University of Science and Technology), the Nord-Trøndelag County Council, Central Norway Health Authority and the Norwegian Institute of Public Health.

Contributors X-MM and Y-QS contributed to the study design. AH and Y-QS conducted statistical analyses. AH and X-MM wrote the initial draft of the manuscript. AH, X-MM, YC and Y-QS participated in the data interpretation and 
contributed to the final draft of manuscript with intellectual importance. All authors approved the final version of the manuscript.

Funding The project was supported by The Norwegian Cancer Society (project ID 182688-2016) and The Research Council of Norway 'Gaveforsterkning'. Y-QS was supported by a Researcher grant from The Liaison Committee for education, research and innovation in Central Norway (project ID 2018/42794). The funders had no role in study design, data collection and analysis, decision to publish, or preparation of the manuscript.

Competing interests None declared.

Patient consent for publication Not required

Ethics approval The current study was approved by the Norwegian Regional Committees for Medical and Health Research Ethics (2015/1562/REK sør-øst).

Provenance and peer review Not commissioned; externally peer reviewed.

Data availability statement Data may be obtained from a third party and are not publicly available. Data from the Nord-Trøndelag Health Study (HUNT) that is used in research projects will, when reasonably requested by others, be made available on request to the HUNT Data Access Committee (hunt@medisin.ntnu.no). The HUNT data access information describes the policy regarding data availability (https:// www.ntnu.edu/hunt/data).

Open access This is an open access article distributed in accordance with the Creative Commons Attribution Non Commercial (CC BY-NC 4.0) license, which permits others to distribute, remix, adapt, build upon this work non-commercially, and license their derivative works on different terms, provided the original work is properly cited, appropriate credit is given, any changes made indicated, and the use is non-commercial. See: http://creativecommons.org/licenses/by-nc/4.0/.

\section{ORCID iDs}

Xiao-Mei Mai http://orcid.org/0000-0002-0426-7496

Yi-Qian Sun http://orcid.org/0000-0002-9634-9236

\section{REFERENCES}

1 NCD Risk Factor Collaboration (NCD-RisC). Trends in adult bodymass index in 200 countries from 1975 to 2014: a pooled analysis of 1698 population-based measurement studies with $19 \cdot 2$ million participants. Lancet 2016;387:1377-96.

2 GBD 2015 Obesity Collaborators, Afshin A, Forouzanfar MH, et al. Health effects of overweight and obesity in 195 countries over 25 years. N Engl J Med 2017;377:13-27.

3 Palacios C, Gonzalez L. Is vitamin D deficiency a major global public health problem? J Steroid Biochem Mol Biol 2014;144:138-45.

4 Vanlint S. Vitamin D and obesity. Nutrients 2013;5:949-56.

5 Drincic AT, Armas LAG, Van Diest EE, et al. Volumetric dilution, rather than sequestration best explains the low vitamin D status of obesity. Obesity 2012;20:1444-8.

6 Wortsman J, Matsuoka LY, Chen TC, et al. Decreased bioavailability of vitamin D in obesity. Am J Clin Nutr 2000;72:690-3.

7 Foss YJ. Vitamin D deficiency is the cause of common obesity. Med Hypotheses 2009;72:314-21.

8 Young KA, Engelman CD, Langefeld CD, et al. Association of plasma vitamin $D$ levels with adiposity in Hispanic and African Americans. $J$ Clin Endocrinol Metab 2009;94:3306-13.

9 González-Molero I, Rojo-Martínez G, Morcillo S, et al. Hypovitaminosis D and incidence of obesity: a prospective study. Eur $J$ Clin Nutr 2013;67:680-2.

10 Mai X-M, Chen Y, Camargo CA, et al. Cross-sectional and prospective cohort study of serum 25 -hydroxyvitamin $D$ level and obesity in adults: the HUNT study. Am J Epidemiol 2012;175:1029-36.

11 LeBlanc ES, Rizzo JH, Pedula KL, et al. Associations between 25 -hydroxyvitamin $D$ and weight gain in elderly women. $J$ Womens Health 2012;21:1066-73.

12 Larsen SC, Ängquist L, Moldovan M, et al. Serum 25-hydroxyvitamin $\mathrm{D}$ status and longitudinal changes in weight and waist circumference: influence of genetic predisposition to adiposity. PLOS One 2016;11:e0153611.

13 Stenholm S, Vahtera J, Kawachi I, et al. Patterns of weight gain in middle-aged and older us adults, 1992-2010. Epidemiology 2015;26:165-8.
14 Khosravi ZS, Kafeshani M, Tavasoli P, et al. Effect of vitamin D supplementation on weight loss, glycemic indices, and lipid profile in obese and overweight women: a clinical trial study. Int J Prev Med 2018;9:63.

15 Lotfi-Dizaji L, Mahboob S, Aliashrafi S, et al. Effect of vitamin D supplementation along with weight loss diet on meta-inflammation and fat mass in obese subjects with vitamin D deficiency: a doubleblind placebo-controlled randomized clinical trial. Clin Endocrinol 2019;90:94-101.

16 Mason C, De Dieu Tapsoba J, Duggan C, et al. Effects of vitamin $D$ supplementation during weight loss on sex hormones in postmenopausal women. Menopause 2016;23:645-52.

17 Ortega RM, Aparicio A, Rodríguez-Rodríguez E, et al. Preliminary data about the influence of vitamin $D$ status on the loss of body fat in young overweight/obese women following two types of hypocaloric diet. Br J Nutr 2008;100:269-72.

18 Sneve M, Figenschau Y, Jorde R. Supplementation with cholecalciferol does not result in weight reduction in overweight and obese subjects. Eur J Endocrinol 2008;159:675-84.

19 Krokstad S, Langhammer A, Hveem K, et al. Cohort profile: the HUNT study, Norway. Int J Epidemiol 2013;42:968-77.

20 WHO. Obesity: preventing and managing the global epidemic. Report of a who consultation. World Health Organ Tech Rep Ser 2000;894:1-253.

21 Sachs MC, Shoben A, Levin GP, et al. Estimating mean annual 25-hydroxyvitamin $D$ concentrations from single measurements: the multi-ethnic study of atherosclerosis. Am J Clin Nutr 2013;97:1243-51.

22 Ross AC, Taylor CL, Yaktine AL, et al. Dietary reference intakes for calcium and vitamin D. Washington, DC: The National Academies Press, 2011.

23 Sun Y-Q, Langhammer A, Skorpen F, et al. Serum 25-hydroxyvitamin $\mathrm{D}$ level, chronic diseases and all-cause mortality in a populationbased prospective cohort: the HUNT study, Norway. BMJ Open 2017;7:e017256.

24 Brumpton BM, Langhammer A, Ferreira MAR, et al. Physical activity and incident asthma in adults: the HUNT study, Norway. BMJ Open 2016;6:e013856.

25 Mai X-M, Langhammer A, Chen Y, et al. Cod liver oil intake and incidence of asthma in Norwegian adults-the HUNT study. Thorax 2013;68:25-30.

26 Stevens J, Truesdale KP, McClain JE, et al. The definition of weight maintenance. Int J Obes 2006;30:391-9.

27 Paige E, Korda RJ, Banks E, et al. How weight change is modelled in population studies can affect research findings: empirical results from a large-scale cohort study. BMJ Open 2014;4:e004860.

28 Zou G. A modified poisson regression approach to prospective studies with binary data. Am J Epidemiol 2004;159:702-6.

29 Caan B, Neuhouser M, Aragaki A, et al. Calcium plus vitamin D supplementation and the risk of postmenopausal weight gain. Arch Intern Med 2007;167:893-902.

30 Soares MJ, Murhadi LL, Kurpad AV, et al. Mechanistic roles for calcium and vitamin $D$ in the regulation of body weight. Obes Rev 2012;13:592-605.

31 Abbas MA. Physiological functions of vitamin $D$ in adipose tissue. $J$ Steroid Biochem Mol Biol 2017;165:369-81.

32 Sergeev IN. Vitamin D status and vitamin D-dependent apoptosis in obesity. Nutrients 2020;12:1392.

33 Garawi F, Devries K, Thorogood N, et al. Global differences between women and men in the prevalence of obesity: is there an association with gender inequality? Eur J Clin Nutr 2014;68:1101-6

34 Jääskeläinen T, Männistö S, Härkänen T, et al. Does vitamin D status predict weight gain or increase in waist circumference? results from the longitudinal health 2000/2011 survey. Public Health Nutr 2020;23:1266-72.

35 Vogt S, Zierer A, Laxy M, et al. Association of serum vitamin D with change in weight and total body fat in a German cohort of older adults. Eur J Clin Nutr 2016;70:136-9.

36 Hankinson AL, Daviglus ML, Bouchard C, et al. Maintaining a high physical activity level over 20 years and weight gain. JAMA 2010;304:2603-10.

37 Hibler EA, Sardo Molmenti CL, Dai Q, et al. Physical activity, sedentary behavior, and vitamin D metabolites. Bone 2016;83:248-55.

38 Darmon N, Drewnowski A. Does social class predict diet quality? Am J Clin Nutr 2008;87:1107-17. 